\title{
Towards nZEB: modular pre-assembled steel systems for residential buildings
}

\author{
E. Antonini, D. Longo \& V. Gianfrate \\ Department of Architecture, University of Bologna, Italy
}

\begin{abstract}
The recent EU Directives 2010/31 and 2012/27 provide for the standard of nearly zero energy buildings for new constructions, aiming at a better quality for the built environment through the adoption of high performance solutions. This challenge creates new opportunities for pre-assembled construction systems, offering high levels of performance, while reducing construction time and environmental impacts related to the whole building process and to the operations on-site. A research program, carried out by the University of Bologna, Department of Architecture, adopts a holistic approach for integrated design process, focusing on:

- the optimization of modular preassembled building envelope behaviour during the summer in Mediterranean areas, using a simulation model;

- the definition of a comparative assessment of the building envelope performance in relation to the different technical configurations, in terms of Uvalue, thermal phase displacement, thermal mass, $\mathrm{CO}_{2}$ emissions, etc.

This paper outlines the first results of this research, focusing on the comparison of different multilayer envelope configurations, through a method based on the assessment of its energy performance. To optimize the envelope components response to the different thermal conditions a comparative analysis was performed by relating the energy performance to the occupants' thermal comfort. This method of assessment can be adapted to offer a customizable configuration of the modular building system.

Keywords: pre-assembled constructions, sustainability, adaptability, modularity, $n Z E B$ technologies, high performance envelope, steel structure, building industry, customizable solutions.
\end{abstract}




\section{Introduction}

The Energy Performance of Buildings Directive Recast (EPBD Recast) came into force on 9 July 2010. The directive defines a nearly zero energy building as a building that has a very high-energy performance and requires the calculation of a primary energy indicator. The nearly zero or very low energy demand should be largely covered from renewable sources, including those produced on-site or nearby. Member States shall draw up national plans and roadmaps for increasing the number of nearly zero energy buildings. A recent benchmarking study on EPBD implementation recently carried out by REHVA (Seppänen and Goeders [1]), revealed relevant differences in technical regulations adopted by EU countries. These differences have a significant effect on the building industry, and complicate manufacturing, sales, installation, construction and design of buildings in European Single Market (Gianfrate [2]). It can restrain the pressure to build or renovate towards nearly zero energy buildings, which needs a common effort to significantly upgrade of working practices in building sector instead.

The last EU directive 2012/27 faces the challenge to shift to a more energyefficient economy and to accelerate the spread of innovative technologies, improving the competitiveness of European industry, boosting economic growth and creating high quality jobs in several sectors related to energy efficiency.

"nZEB technology" (REHVA [3]) or packages of technologies are all the technical means which improve the building energy performance in order to fulfil the national nZEB requirements. These include a large range of techniques, such as better insulation and air-tightness of the building envelope, replacing or improvement of windows, application of sun screens, installation of PV and thermal solar panels, efficient electrical devices and appliances, high performance HVAC systems, exploiting RES as much as possible.

Among others, the improving of building envelope performances plays a crucial role in reaching nZEB standard, and drives the adoption of high efficient solutions and techniques.

The building envelope is under an intense process of specialization involving all its elements: the improved performances of most of the materials and components need a customized and more effective design of each technical configuration in which they are applied, with positive potential effects on the whole building quality. The "open" systems of building components, as developed in the seventies to replace the "closed" systems, which characterized the first approach to industrialization, are now articulated in sets of high-specialized components and subcomponents, with a large range of applications.

Dry assembled systems are emerging as a successful evolution of this open system approach to building industrialization. The assembling by mechanical joining allows a layer-by-layer configuration of each building element, whose performances can be modulated adopting the more suitable component for each layer. At the whole building scale, the dry assembling of elements assure the same features of precision, speed, flexibility, adaptability and reversibility, despite the increased complexity of the elements. When the required levels of performance are very high, like in nZEB buildings, these techniques can provide very effective 
results: it explains the fast market penetration of the dry-assembled systems, whose diffusion is expected to increase further in the next future.

\section{Modular preassembled system}

Modular preassembled construction provides for a specific type of prefabrication procedure, where the building components are assembled off-site in modules. These modules are built in factory, shipped to the site, installed, and connected to create a complete building. Faster speed of construction and - thus - faster return on the investment are some of the major drivers for this type of construction which includes a variety of scales of intervention, from single-house to high-rise, and different functions, including residential, student housing, public buildings and commercial (Azari [4]). Other benefits consist in more safe and productive working conditions in the manufacturing sector, which is of particular value in extreme climate regions, as well as benefits in transportation and logistics.

However, design and construction of modular buildings require high levels of collaboration among project parties, especially architect, structural engineer and manufacturer, from the early design process stages, taking into account the important constraints related to transportation of modules, logistics for installation, permits and schedules of inspection. More specifically, weight and size of the modules to be transported and installed, and the structural capability of the final product need to be carefully considered in the design of modular buildings.

A 2007 study indicated that, to perform a cost effective modular construction, the following strategies are required (Tam et al. [5]):

- complete mechanizing of the production process;

- eliminating the amount of site work required as much as possible;

- maximizing the usage of recycled materials for prefabricated building components.

Preassembled components, compared to traditional construction processes, aim at reducing costs for the same quality levels and facilitating the installation/dismantling/re-use of components. It also facilitates the re-use of waste from both the construction and industrial sectors.

\section{Modular preassembled steel systems research lines}

A research program, carried out by the research group of Technology for architecture from the University of Bologna - Department of Architecture (DA), adopts a holistic approach for integrated design process, focusing on:

1. The optimization of building envelope (realized with modular preassembled elements) behaviour for residential units during summer in the Mediterranean areas, using a simulation model for testing new materials and components and assessing the possible integration of structure and equipment (Boeri and Longo [6]); 
2. The definition of a comparative assessment of the building envelope performances in relation to the different technical configurations, in terms of $\mathrm{U}$-value, thermal phase displacement, thermal mass, $\mathrm{CO}_{2}$ emissions related impact of the building energy consumption, and smart integration of structure, equipment and services, including RES installations.

This paper outlines the first results of the research - mentioned above - on modular preassembled construction with steel frame, focusing on the comparison of different multilayer envelope configurations, through a method based on the assessment of its energy performance.

This research aims at analysing the materials and components behaviour in the entire life cycle of buildings and, consequently, checking the best performance of the envelope products, taking into account important aspects such as the overall thermal performance and airtightness. This research investigates innovative manufacturing processes to limit pre-fabrication costs and facilitate the building integration processes, considering the challenge of aesthetic factor for new and existing buildings.

The objective is to demonstrate how a new paradigm for the concept and construction of buildings can be conceived as an entirely factory-based process that creates advantages for construction through an industrial systems technology transfer.

Prototypes and pilot implementations in real industrial settings represent a clear added value, with the involvement of SME in the manufacture of prefabricated modules.

The research of the UNIBO-DA recognizes the housing industry inefficiencies and fragmentation caused by the slow adoption of new technologies (Giles [7]) and promotes a shift of paradigm for the construction sector that uses industrialized manufacturing models and technology transfer in the design and procurement process, based on final climatic and environmental performance.

The overarching objective of this research is to create a new way of conceptualizing technologically innovative housing design that integrates environmental and economic sustainability. This was conceived through a focus that:

- creates advantages for construction using factory-based manufacturing methods;

- innovates construction concepts using entirely pre-assembled modular components;

- integrates low-energy/whole-house design and sustainable technologies.

Quantify and evaluate dynamic energy performances of the opaque envelope in a hot climate is a crucial and common field of investigation at an international level. Studies and research underlines the importance of summer thermal conditions control, through the adoption of light envelopes with a specific combination and position of construction materials layers (using in the same stratigraphy both standard and innovative materials). 
A demonstration activity commissioned by a national SME specialized in steel extrusion profiles constituted the occasion to check the research lines of preassembled modular construction systems. The steel company was interested in the development and implementation of a Mediterranean house building with high thermal performance. The research applied investigated the definition of modular preassembled envelope, adaptable to the steel structure designed by the SME client.

Studies and simulations investigated innovative materials, components and systems classified as green construction technologies, and high performance insulating materials available in the market. The purpose is to check the features of these new technologies and their performances, by simulating the behaviour of a range of pilot cases of buildings. The design brief for the demonstration project focused on the use of modular construction to increase quality without increasing initial building costs, by adopting the following main strategies:

- standardization of components (i.e. reiteration of component and joint details);

- reduction of joints number to increase onsite craftsmanship;

- reduction in numbers and weight of components to ship;

- minimize the amount and the complexity of work done onsite (foundation prework and onsite preassembly).

\subsection{The case study}

The research work aimed to define a high performance and adaptable envelope for the Mediterranean modular residential unit. The steel structural model was elaborated by the steel company, interested to improve its market through the creation of modular buildings for residential sector. The sustainable house uses technological innovation to supply comfortable living conditions, while minimizing energy consumption. It is a lightweight modular, transportable, residential unit

The first step of the DA research was a thorough analysis of the adopted configurations, allowing to identify the main features and levels of performance. The system was also compared with the alternative solutions available on the market for internal partitions, selecting the most traditional and recurring ones. The study identified the following key components that contribute towards an integrated strategy and have become the key features in the project design concept of a modular residential unit realized with pre-assembled steel systems:

- creation of groups of 'parts' to facilitate sub-assembly manufacture;

- ability to achieve tight tolerances between steel components and units;

- exploitation of the high-strength and stiffness-to-weight ratio in steel to economically achieve midrise construction heights;

- using of sub-assemblies to allow customized design of modules and facilitate future flexibility.

The main aim of the case study was to define a building envelope with high thermal performances, and to allow a good market placement of the modular 
residential unit, through the creation of a nZEB that overpass the regulatory limits of 20-20-20 Directive (2010/31/CE).

The challenges of the research work related to the modular preassembled construction design (Antonini and Landriscina [8]) were:

- optimization of the installation stages;

- optimization of the dimension of each component of the envelope;

- optimization of joint systems;

- reduction or removal of thermal bridges;

- thermoigrometric check and envelope behaviour in different climate contexts;

- integration of plant design.

The performance behaviour of the envelope aimed to reach the following environmental goals for building sector:

- reducing the construction site operation impact through the adoption of tools and technologies with a less environmental footprint;

- reducing energy and raw materials consumption during the production process of building components;

- reducing energy loss during the lifecycle of the building;

- facilitating the transport, the mobilization and the assembly thank to the lightweight of materials and components;

- obtaining simplicity and fastness during installation stages;

- increasing high fire protection, thermal and acoustic performances.

This study investigated and elaborated technological solution for each component of the building envelope: walls, ground floor, roof, windows, but the main focus was on the features of the vertical envelope.

\subsubsection{The vertical envelope}

The envelope defined is a multi-skinned wall, made of different layers that comply with multiple goals:

- it is lightweight;

- it is modular and transportable;

- it provides high thermal resistance and low conductivity;

- it is made of customizable materials;

- it is prefabricated.

The thermal conservation features of the envelope are of paramount importance for the performance of the house. They are assured by a multi-layered system of materials, where each layer meets a specific purpose (in terms of thermal, acoustic, structural performances), compatible and in collaboration with the others, to obtain an assessed performance of the whole building.

This research works to optimize the modular assembled envelope in term of balance between weight, volume and performances. 
Figures 2 and 3 present a section of the residential module vertical wall and the joints with floor and roof.

The structure of preassembled modular envelope panels presents a double lightweight steel framework, in accordance with the main steel structure of the building. This framework is jointed to the primary structure with clamp mechanical systems.

The exterior side of the vertical wall is covered with a double layer of calcium silicate panels of 12-15 mm of thickness. External panels are of $15 \mathrm{~mm}$, internal ones are of $12 \mathrm{~mm}$ with a weight of $1200 \mathrm{~kg} / \mathrm{mc}$. The project foresees in the middle of the wall another series of calcium silicate panels to stiffen the structural performance of the vertical envelope.

The calcium silicate improves also the acoustic insulation and augments the collapse time, in case of fire. The gap between the calcium silicate slabs series include a double sheet of insulating panels made of different insulation materials, customizable in relation to climate condition of house location. Each insulating sheets has a different density. First the lower density panels improve the thermal insulation, and then the higher density panels improve also the acoustic insulation. A breathable barrier film ensures the protection from the external humidity, while it remains permeable to air and humidity from the inside out. This film guarantees the natural transpiration of the wall and prevents the formation of interstitial condensation during the winter.

The articulation of different layers improves the acoustic and thermal insulation, and provides space for hosting other components as plant systems.

The customizable insulation layer is addressed to natural or green materials that allow performance durability and recyclability at the end of the lifecycle.

Each wall is insulated in the upper and lower side with a neoprene rubber to soften conduction vibration.

Table 1: $\quad$ The wall definition.

\begin{tabular}{|l|c|}
\hline Wall layers & Thickness \\
\hline Plasterboard & $\mathbf{0 . 8} \mathbf{~ c m}$ \\
\hline Calcium silicate panel & $1.2 \mathbf{c m}$ \\
\hline Insulating layer & $7.5 \mathbf{~ c m}$ \\
\hline Calcium silicate panel & $1.0 \mathbf{~ c m}$ \\
\hline Calcium silicate panel & $1.2 \mathbf{~ c m}$ \\
\hline Insulating layer & $\mathbf{5 . 5} \mathbf{~ c m}$ \\
\hline Vapour barrier & $\mathbf{0 . 1} \mathbf{~ c m}$ \\
\hline Insulating layer & $10 \mathbf{c m}$ \\
\hline Calcium silicate panel & $1.2 \mathbf{c m}$ \\
\hline Plaster & $\mathbf{1 . 0} \mathbf{~ c m}$ \\
\hline Total thickness & $\mathbf{3 0 . 5} \mathbf{~ c m}$ \\
\hline
\end{tabular}


The use of a high thermal capacity building envelope, back to back with programmable materials and software control methods, can have significant contribution in optimizing energy performance.

The thermal mass of the wall is $30.5 \mathrm{~cm}$ in thickness to secure high-level heat transmission resistance.

The house wall has a theoretical calculated value of $U$ between 0.19 and $0.14 \mathrm{~W} / \mathrm{m}^{2} \bullet \mathrm{K}$, depending on the insulating material choice (as shown in Table 2).

Table 2: Value of thermal performance of the module, changing the exterior layer of wall mass.

\begin{tabular}{|l|c|c|c|}
\multicolumn{1}{|c|}{ Thermal properties } & Wood fibreboard & Cork & Polystyrene \\
\hline Thermal transmittance $\mathrm{U}\left[\mathrm{W} / \mathrm{m}^{2} \mathrm{~K}\right]$ & 0.168 & 0.193 & 0.147 \\
\hline Attenuation factor $\mathrm{Fd}[\%]$ & $8.92 \%$ & $9.72 \%$ & $15.28 \%$ \\
\hline Thermal lag $\varphi[\mathrm{h}]$ & $15 \mathrm{~h} 02^{\prime}$ & $15 \mathrm{~h} 06$ & $10 \mathrm{~h} 51$ \\
\hline Periodic thermal transmittance $\mathrm{Y}\left[\mathrm{W} / \mathrm{m}^{2} \mathrm{~K}\right]$ & 0.015 & 0.019 & 0.22 \\
\hline Surface mass $\left[\mathrm{Kg} / \mathrm{m}^{2}\right]$ & 101 & 180 & 84 \\
\hline
\end{tabular}

The research units checked the thermal performance of the modular unit envelope improving:

- thermal insulation, minimization of thermal bridging;

- airtightness;

- control of condensation.

For the light steel construction, the research unit adopted the warm frame framing principle (Lawson et al. [9]), where the majority of insulation is places externally to the structure (Figures 1 and 2).

An additional insulation layer is placed between the two calcium silicate panels to improve the thermal and acoustic performance of the envelope. The thermal bridges occurred at points of discontinuity in the structure (corners, joints between the steel construction system and the multilayer envelope, windows) are dealt with the apposition of insulating panels (as shown in Figure 3). The module

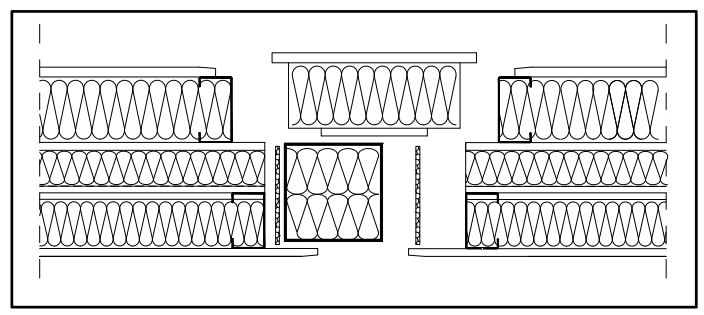

Figure 1: The warm frame around the steel column. 


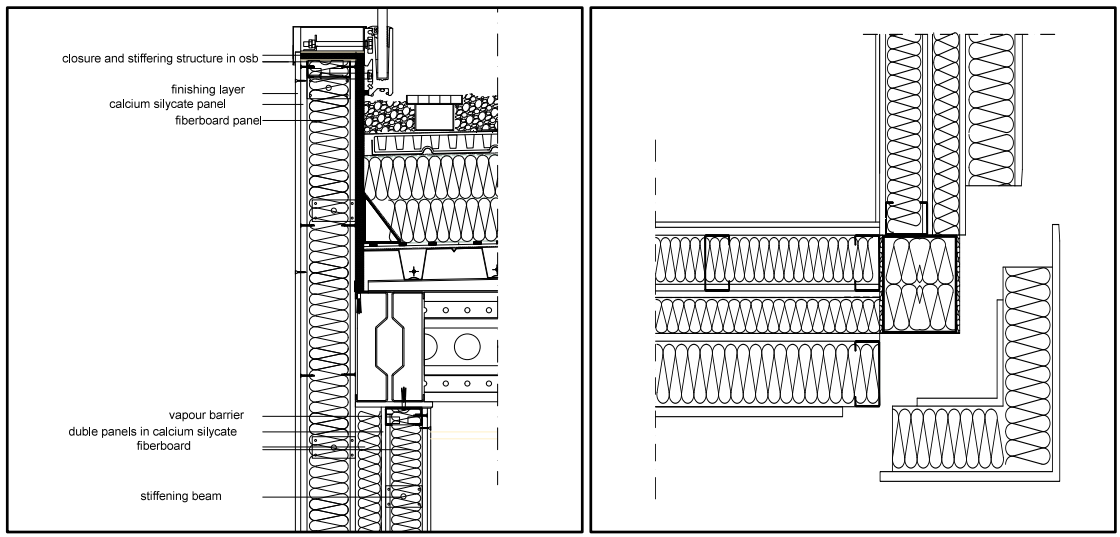

Figure 2: Vertical section of the wall.

Figure 3: The insulated corner.

production will be articulated in different dimension, with the variation of a pillar section of the structure, to allow the availability of a selection of closure elements, to answer to the different plant integration, thermal and acoustic requirements.

The module will join the benefit of the dry assembled system to the preassembly solutions, with the achievement of an improved building product, under the technological and performance point of view, the installation timing, and the O\&M activities aspects. This research work is focused on the design of a single level building with a regular drawing, but the modularity of the preassembled construction system, and the reversible joints allow other configuration: multilevel buildings, different articulation, etc.

The simplification of operations of installation, the dry assembly procedures, the preassembly of special modules for bathroom allow the integration with the plant design. These features contribute to the deep flexibility of internal spaces and of plant network installation (horizontal and vertical configurations), and ease operation and maintenance activities during the lifecycle of the building.

Special items are wall module with preassembled water and sanitary system integrated, completed with kit furnishing. These modules are designed through the joint between the steel framework of the wall and the support structure of sanitary, with the aim to supply assembly pieces, ready to insert the hydro sanitary system connections (Figure 4). The facilitation of inspection offers the possibility of maintenance intervention through simple disassembly operations with positive consequence on cost and time saving. The flexibility of the preassembled module permits us to remove or change the position of each wall module, in every moment, with the removal of the plasterboard layer and the consequent handling of the preassembled module that could be placed again to meet the new needs (Figure 5). 


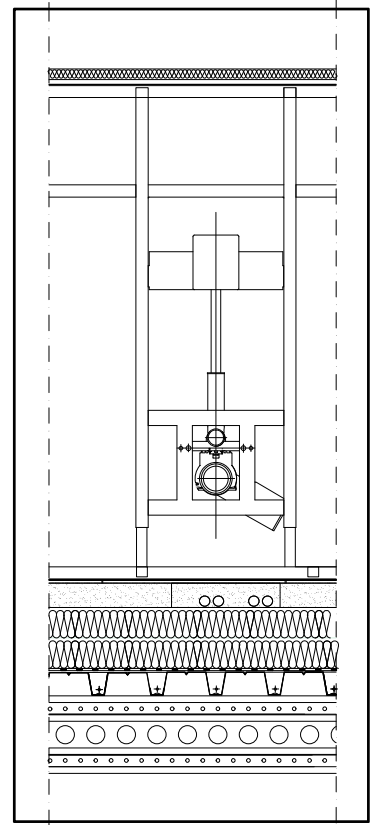

Figure 4: Wall module of the bathroom with the preassembled integration of a hydrosanitary system.

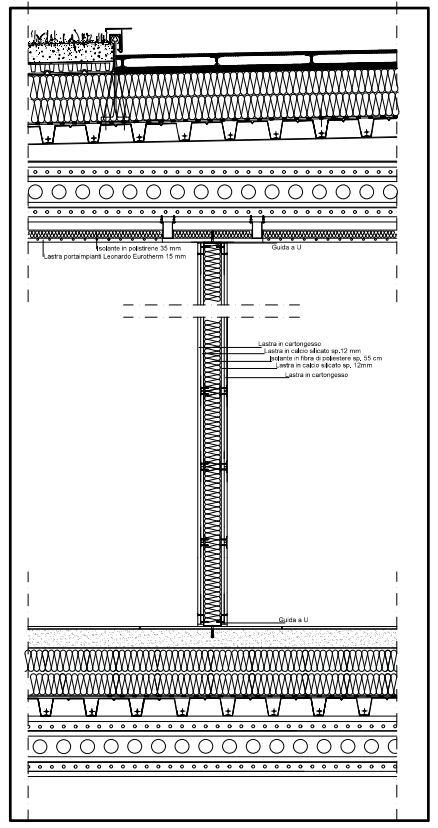

Figure 5: Internal preassembled wall.
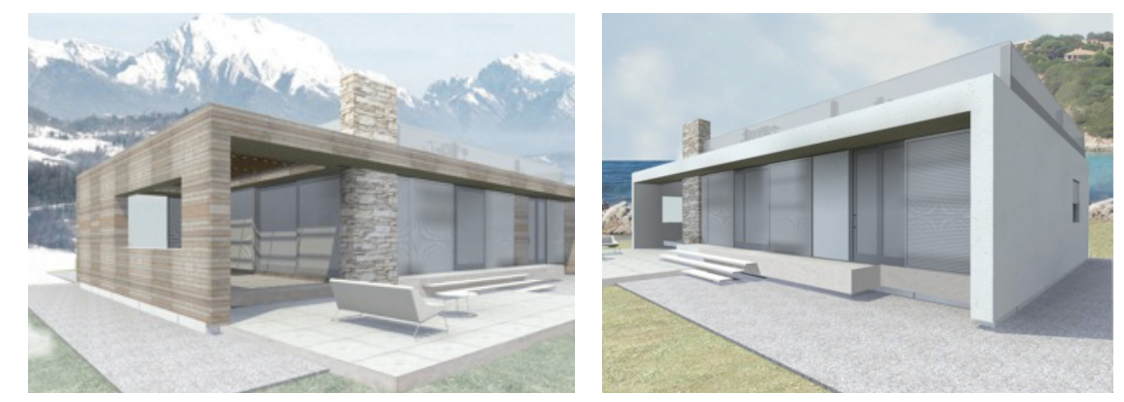

Figure 6: Simulation of different configurations of the prefabricated building.

\section{Conclusion}

Improving the energy efficiency of residential buildings is critical in addressing the global energy challenge. 
This module is a residential unit that combines a high thermal mass envelope, a customizable configuration and a simplification in operation and maintenance activities, to ensure comfortable interior conditions, at minimum energy cost.

Determining an architecture that allows maximizing the thermal and light gains without restricting the openness of the design was a central consideration. Computer simulation pointed towards optimum strategies of orientation, material selection and distribution.

A parallel consideration was to reduce the construction time and to ensure the efficiency of the assembly process.

The research outputs optimize energy performance, automate climate control, and encourage ecologically responsible behaviour. Furthermore, it introduces a consistent construction approach:

- modular design, at every scale;

- efficient assembly; disassembly; transportability;

- material selection;

- efficient combination of conservative, selective and responsive modes of management;

- performance-driven design, in view of aesthetic, social and cultural effects;

- beyond the capacity to minimize energy consumption, sustainability is about establishing consistent building principles.

The modular construction approach provides an increase in the sustainability of a modular project. According to a report published in the Journal of Industrial Ecology, modular construction has lower impacts, on average, than on site construction considering all the environmental impact categories studied (Quale et al. [10]).

Off-site modular construction provides a factory setting in which testing and utilizing technological advancements. This is a result of the ability for a factory to mock-up entire modules before production as well as the ability to take advantage of reproduction of a single or few different types of modules.

Second, there is not a lot of on-site construction that typically produces significant particle matter, run off and pollutants.

The use of steel is also beneficial because the recyclability is much higher than other building materials. Finally, the modularity increases the ease associated with the disassembling of parts required in order to recycle building materials after the building is no longer used.

The life of the building plays a key part in determining its sustainability. A prefab realization allows to ensuring a higher quality in construction and, in turn, a long-life of the structure. The design method based on assessment can be adapted to offer a customizable configuration of the modular building system in terms of insulation, size and positioning of the windows, materials and technologies for building façade.

The research unit developed the building system, based on reconfigurable subassemblies that will facilitate mass customization, hence breaking away from traditional building approaches. A set of solutions was pointed out and simulations were performed in order to test thermal and energy behaviour both in summer and 
winter conditions. Furthermore, a series of simulations was performed to assess and compare different cladding solutions by adopting different materials and patterns. The simulation tool, adopted to check the adaptability (with Termolog software) of different solutions, can be considered as a support for the decision makers with reference to the choices related to the properties of the envelope components, consequently reaching the highest possible level of energy performances. The modular assembly approach allows to obtain a great flexibility in terms of spatial conditions, technologies implementation (with better performance materials and components), transformation and substitution of layers for maintenance during the lifecycle of the building.

A "customized sustainability" approach was adopted to determine how achieving optimal thermal performance of the building envelope. This approach involved the investigation of complete regional weather data and dynamic simulation for lighting and sun-path, for three specified geographic location in Italy, during the 12 months of the year. (Figure 6).

\section{References}

[1] Seppänen O., Goeders G. Benchmarking Regulations on Energy Efficiency of Buildings. Executive summary. Federation of European Heating, Ventilation and Air-conditioning Associations - REHVA, May 5, 2010.

[2] Gianfrate V., "Normativa e prodotti edilizi: verso la sostenibilità de costruito", Il Progetto Sostenibile n.32, Edicom Edizioni, July 2013.

[3] REHVA, Assessment of the state of the art of existing technologies to support nZEB renovations, NEZEH project (IEE) report, December 2013.

[4] Azari, R., Modular Prefabricated Residential construction. Constraints and Opportunities, University of Washington, PNCCRE Technical Report, Skanka USA, 2013.

[5] Tam, Vivian W. Y., C. M. Tam, S. X. Zang, and William C. Y. Ng. 2007. "Towards Adoption of Prefabrication in Construction." Building and Environment, Number 42, 2007.

[6] Boeri A., Longo D., Energy efficiency in buildings in southern Europe: challenges and design strategies. International journal of sustainable development and planning, WIT, Vol. 6 No. 4, pp. 522-536, 2011.

[7] Giles H., Prefabricated Construction using Digitally Integrated Industrial Manufacturing, University of Michigan, The ARCC Journal of Architectural research, Vol. 5, No. 2, 2008.

[8] Antonini E., Landriscina G., (edited by), Innovazione, efficienza e sostenibilità del costruire. I risultati delle azioni di ricerca e trasferimento tecnologico del Laboratorio LaRCo e del Centro ICOS, BOLOGNA, RICOS, p. 158, 2007.

[9] Lawson M., Ogden R. and Goodier C., Design in Modular Construction, CRC Press, 2014.

[10] Quale, J., Eckelman, M. J., Williams, K.W., Sloditskie, G., Zimmerman, J.B. (2012). Construction Matters: Comparing Environmental Impacts of Building Modular and Conventional Homes in the United States. Journal of Industrial Ecology, Vol. 16, No. 2, 1 April 2012. 